Original article

\title{
Sociodemographics, clinical profile and health promotion behaviour of people with type 2 diabetes mellitus
}

\author{
Athira Kalangadan, Shifa Puthiyamadathil, Snana Koottat, \\ Shejila Chillakunnel Hussain Rawther (PhD)*, Assuma Beevi T M (PhD) \\ MIMS College of Nursing, Puthukode Post, Malappuram, Kerala, India
}

\section{A R T I C L E I N F O}

\section{Keywords:}

Diet

Exercise

Health promotion behaviour

Physical activity

Type 2 diabetes mellitus

\begin{abstract}
A B S T R A C T
Aim: The aim of the study was to assess the health promotion behaviour of type 2 diabetic patients. Background: Diabetes mellitus is the most prevalent and a key healthcare problem throughout the world. Health promotion behaviour is known to be a major component in managing type 2 diabetes.

Methods: This cross sectional study was conducted among 60 samples using purposive sampling technique. Sociodemographic and clinical proforma, health promotion behaviour questionnaire were used to collect data. Data were analyzed using SPSS version 16.

Results: The study revealed that only $15 \%$ of samples had adequate health promotion behaviours. Health promotion behaviour is associated with occupation, duration of diabetes, and family history of diabetes.

Conclusion: The practice of health promotion behaviour varies among patients, individually tailored interventions and motivation is needed.
\end{abstract}

\section{Introduction}

Diabetes is a chronic disease affecting people around the world. The prevalence of Diabetes mellitus is increasing globally and was the seventh leading cause of death in 2016. Diabetes prevalence has been rising more rapidly in middle- and low-income countries. ${ }^{1}$

The diabetic population in India is rising at a faster rate and by 2025; the number is predicted to increase to 69.9 million and by 2030 to 80 million. India is set to become the world's capital of diabetes. The major reason behind this prevalence is the lack of awareness among the patients who fail to achieve timely diagnosis and medical attention. ${ }^{2}$

Changes in dietary habits including taking high calorie food with low nutritional value, lack of physical activity alcohol consumption and smoking are the major causes of diabetes. ${ }^{3}$ Few studies have investigated that life style and human behaviours are responsible for development of diabetes. ${ }^{4-8}$

According to an article published by American Diabetes Association, the life style modification behaviours for diabetes includes healthy eating, monitoring, doing physical activity, taking medications, reducing risk and problem solving. ${ }^{9}$

Some studies proved that health promoting behaviours are positively associated with diabetes control. Practicing diabetes prevention programmes contributed to reduction in incidence rates. ${ }^{10-13}$ Most of the studies scope was derived from perspectives like diet, physical activity or exercise, foot care, social support, self care and risk taking. ${ }^{14,15}$

A healthy lifestyle, health and preventive behaviors, as well as healthy nutrition habits play a key role in treating T2DM as well as limiting its complications.So it is essential to maintain a health promoting behaviour to prevent complications from diabetes and to maintain a superior quality of life. ${ }^{16,17}$

It was reported by Chen et al. that Patients with higher health promotion scores had better diabetic control. Less physical activity was found among those addicted to cigarette, alcohol and betel nut consumption. The findings suggest that health care providers should assess health promoting behaviors first for each diabetic patient before giving counselling. ${ }^{15}$

Since health promotion behaviours and its adherence are necessary for effective control of diabetes and the investigators during their clinical experience identified that there are many Diabetes mellitus patients who don't have adequate awareness regarding proper practice of health promotion behaviours, it was a pressing need to conduct such a study on practice of health promotion behaviour. To the best of our knowledge only few studies from India have investigated the actual health promotion behaviour in people with diabetes.

\footnotetext{
* Corresponding author. Department of Medical Surgical Nursing, MIMS College of Nursing, Puthukode, Malappuram, Kerala, India.

E-mail address: drshejila@gmail.com (S.C. Hussain Rawther).
} 


\section{Objective}

The objective of the study was to assess the health promotion behaviour of people with type 2 Diabetes Mellitus.

\section{Methods}

\subsection{Study design and setting}

This cross sectional study was conducted in General Medicine Department of a tertiary care hospital, Kerala, India. The study was conducted between April 2018 and May 2018. A total of 60 samples were selected by using purposing sampling technique.

\subsection{Participants}

The sample size for this study was calculated based on a similar study assessing health promotion behaviour with $80 \%$ power and $5 \%$ error and the sample size required was $60 .{ }^{18}$ The sampling technique used was purposing sampling technique. Inclusion criteria were i) patients diagnosed with type 2 diabetes mellitus ii) Male or female aged between 30 and 60 years (Type 2 diabetes more prevalent in this age group) iii) patients who can read and write Malayalam or English. The exclusion criteria were i) patients those who are mentally disabled ii) critically ill patients.

\subsection{Instruments}

Three different instruments were used in this study namely sociodemographic proforma, clinical proforma and health promotion behaviours self reported scale. Sociodemographic proforma consisted of 6 items which include age, gender, marital status, educational status, occupational status and income. Clinical proforma included height, weight, BMI, co morbidity status, smoking status, duration of diabetes and family history of diabetes. Health promotion behaviours self reported scale prepared by the researchers consisted of 25 items. First 14 items were related to participants' actual health practice and next 11 items were some statements related to their health promotion believes. The minimum score was 40 and maximum score was 91. Health promotion behaviour score was categorised into inadequate (25-50),minimal (51-75)and adequate (76-100).

All the instruments were validated by 7 experts from Nursing field. The reliability of the instrument was found to be 0.72 (internal consistency method).

\subsection{Ethical considerations}

The present study was reviewed and approved by Institutional Research Committee and Ethics committee (MIMS/IEC/G/04/18). The investigators followed Indian Council of Medical Research ethical guidelines and principles in Declaration of Helsinki. A Participant Information Sheet (PIS) which explains every aspect of the study was given and a written informed consent was obtained from the participants before starting of the study.

\subsection{Data collection}

Before the actual collection of the data, the investigator explained the nature of the study to the participants and a Participant Information Sheet was given. A written informed consent was obtained from the participants and confidentiality of the information and anonymity was assured.

Data were collected from the samples by administering self reported questionnaires of sociodemographic profile and health promotion behaviour. Clinical profile was retrieved from patients' case sheets. Data were collected from outpatients visited General Medicine department of a tertiary care hospital during April 2018 to May 2018.The average time taken to complete the data collection form varied from 15 to $20 \mathrm{~min}$. The data were collected by 3 investigators.

\subsection{Data analysis}

Descriptive statistics like frequency and percentage were used to describe study participants demographic and clinical characteristics and to present health promotion behaviour scores. Chi-square was used to find the association of sociodemographic and clinical variables with health promotion behaviour scores.SPSS version 16 was used to analyse data. The results were presented using tables and figures and summarised narratively.

\section{Results}

\subsection{Sociodemographic characteristics of participants}

Out of sixty participants, $56.67 \%(\mathrm{n}=34)$ were males and $43.33 \%$ $(\mathrm{n}=26)$ were females. The mean age of the group was $53.07 \pm 5.09$ years. Majority of them (83.33\%) were married and living with family. Most of the participants had only primary education (43.34\%), 53.33\% were unemployed and most of them $(41.67 \%)$ belonged to the income range of INR 10,001-15,000 Table 1.

\subsection{Clinical profile of the participants}

Participants reported weight and height was considered and BMI was calculated. The mean weight of the participants was $64.3 \pm 4.45 \mathrm{~kg}$.BMI was categorised as per WHO classification. The average BMI was $24.81 \pm 3.46 \mathrm{~kg} / \mathrm{m}^{2} 51.67 \%(\mathrm{n}=31)$ belonged to normal weight category, $41.66 \%(\mathrm{n}=25)$ were in pre obesity category and $6.67 \%(n=4)$ belonged to class1 obesity category. $43.33 \%$ ( $n=26$ ) were suffering from hypertension, $20 \%$ from cardiovascular diseases, $6.67 \%(n=4)$ were from chronic kidney diseases. Only $23.33 \%(n=14)$ were having smoking habit. Seventy percentage of participants were diagnosed with diabetes for more than 5 yrs and

Table 1

Sociodemographic characteristics of participants.

\begin{tabular}{lll}
\hline Sociodemographic characteristics & Frequency & Percentage (\%) \\
\hline Age in years & & \\
Below 44 years & 4 & 6.7 \\
45-50 years & 14 & 23.3 \\
51-55 years & 17 & 28.3 \\
56-60 years & 25 & 41.7 \\
Gender & & \\
Male & 34 & 56.67 \\
Female & 26 & 43.33 \\
Marital status & & \\
Single & 4 & 6.67 \\
Married & 50 & 83.33 \\
Widow/widower & 6 & 10 \\
Education & & \\
Primary education & 26 & 43.34 \\
High school education & 20 & 33.33 \\
Higher secondary education & 6 & 10 \\
Graduation and above & 8 & 13.33 \\
Occupation & & \\
Employed & 22 & 36.67 \\
Unemployed & 32 & 53.33 \\
Retirement & 6 & 10 \\
Income & 72 & 11.66 \\
Below INR 5000 & 76.67 \\
INR 5001-10,000 & & 41.67 \\
INR 10,001-15,000 & & 20 \\
Above INR 15,001 & & \\
\hline
\end{tabular}

$\mathrm{n}=60$.

*INR-Indian Rupee. 
Table 2

Clinical profile of participants.

\begin{tabular}{lll}
\hline $\begin{array}{l}\text { Clinical } \\
\text { Profile }\end{array}$ & Frequency & Percentage (\%) \\
\hline BMI & & \\
$18.5-24.9$ & 31 & 51.67 \\
$25.0-29.9$ & 25 & 41.66 \\
$30.0-34.9$ & 4 & 6.67 \\
$35-39.9$ & 0 & 0 \\
Above 40 & 0 & 0 \\
Co morbidity status & & \\
Cardio vascular disease & 12 & 20 \\
Hypertension & 26 & 43.33 \\
Cancer & 0 & 0 \\
Chronic kidney diseases & 4 & 6.67 \\
None & 18 & 30 \\
Smoking status & & \\
Yes & 14 & 23.33 \\
No & 46 & 76.67 \\
Duration of diabetes & & \\
$<5$ 5yrs & 18 & 30 \\
$>5$ yrs & 42 & 70 \\
Family history of diabetes & & 38.33 \\
Yes & 23 & 61.67 \\
No & 37 & \\
\hline
\end{tabular}

$\mathrm{n}=60$.

*BMI-body Mass Index.

$38.33 \%(n=23)$ had family history of diabetes Table 2 .

\subsection{Description of health promotion behaviour scores}

The minimum score was 40 and maximum score was 91.Health promotion behaviour score was categorised into inadequate (25-50),minimal (51-75)and adequate (76-100).Most of the participants $66.67 \%(\mathrm{n}=40)$ were following only minimal health promotion behaviours, $18.33 \%(\mathrm{n}=11)$ were having inadequate health promotion behaviour and only $15 \%(n=9)$ were following adequate health promoting behaviours. The mean health promotion behaviour score was $66.28 \pm 11.72$ Fig. 1 .

4.4. Association of selected sociodemographic and clinical variables with health promotion behaviour scores

To find out the association between health promotion behaviour and selected sociodemographic and clinical variables, a chi square test was performed. It was observed that occupation $(p=0.01)$, duration of diabetes $(\mathrm{p}=0.01)$, and family history of diabetes $(\mathrm{p}=0.03)$ have association with health promotion behaviour Table 3 .

\section{Discussion}

The current study was conducted to assess the health promotion behaviour of type 2 diabetic patients and to find out the association between health promotion behaviour and selected sociodemographic and clinical variables.

It is clear from the present study that majority of the samples belong to the age group 56-60 years and the mean age of the participants was $53.07 \pm 5.09$ years. This result is in par with the findings of another study conducted in Iran. ${ }^{19}$ In the current study most of the participants were males $(56.67 \%)$ whereas in a study from Egypt, most of the participants were females (58\%). ${ }^{20}$ Most of the participants in our study were married and living with family (83.33\%). Similarly a study conducted in Denmark shows that majority of the samples were married and living with own family (61.6\%). ${ }^{21}$ Studies conducted in Taiwan and Iran are in line with the present study findings that most of the samples had primary education ( $50.4 \%$ and $40.5 \%$ respectively). ${ }^{19,21}$

The mean BMI in the current study was $24.81 \pm 3.46 \mathrm{~kg} / \mathrm{m}^{2 .}$ This finding is consistent with findings of the study conducted by CP Chen et al. ${ }^{22}$ In contrast to the results of our study the duration of diabetes was more than 10 yrs in two studies. ${ }^{19,21}$ Concerning the family history of diabetes the result of our study showed that only $38.33 \%$ had family history. This result is not in agreement with studies conducted in Saudi Arabia and Egypt where more than two third of patients had a positive family history. ${ }^{23,24}$ This may be possibly due to the existence of consanguineous marriages in both countries. In our study we evaluated the existence of co morbidies in our participants but no other studies reported the co morbidities found in their patients.

Our study results revealed that most of the participants $66.67 \%$ were following only minimal health promotion behaviours and only $15 \%$ were following adequate health promoting behaviours with a mean HPB score of $66.28 \pm 11.72$. Similar results were reported that only $25.3 \%$ had right health promoting behaviour and the mean HPB score was $55.88 \pm 18.09 .^{19,20}$

The study results indicated that occupation $(\mathrm{p}=0.01)$, duration of diabetes $(\mathrm{p}=0.01)$, and family history of diabetes $(\mathrm{p}=0.03)$ have association with health promotion behaviour. However none of the other studies compared the association of health promoting behaviour with demographic or clinical variables.

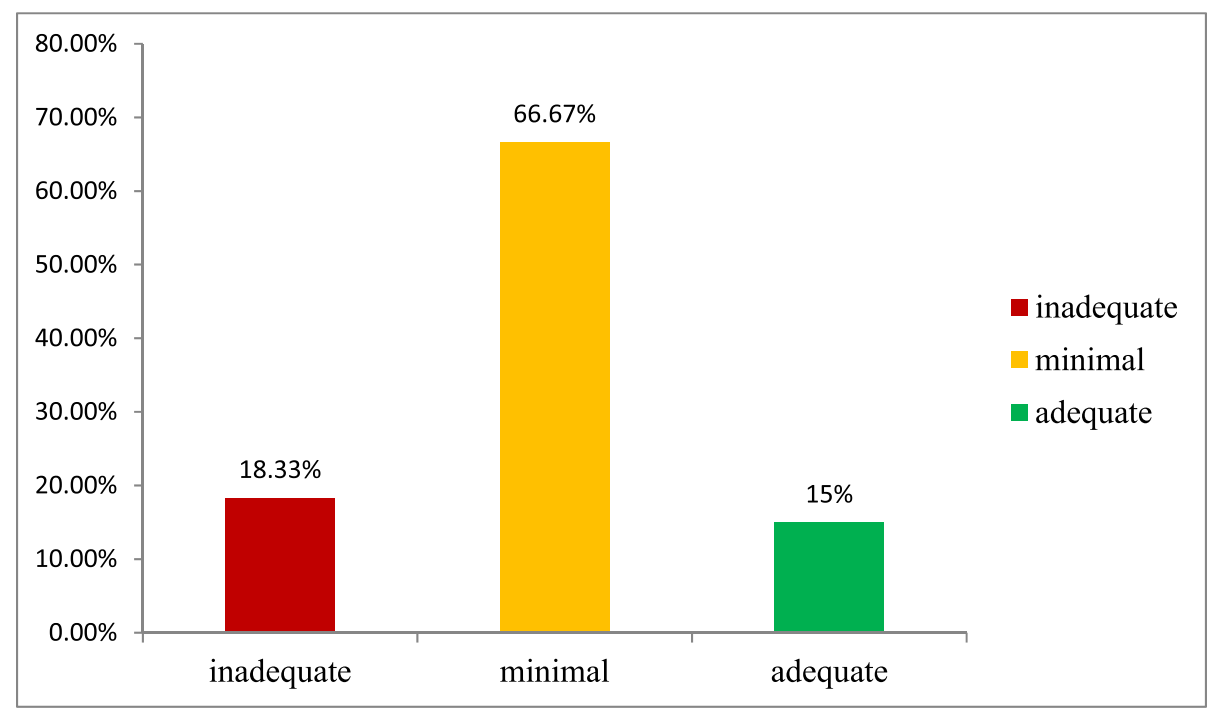

Fig. 1. Health promotion behaviour category. 
Table 3

Association between health promotion behavior and selected socio demographic and clinical variables.

\begin{tabular}{|c|c|c|c|c|c|c|}
\hline \multirow[t]{2}{*}{ Sociodemographic \& clinical characteristics } & \multicolumn{3}{|c|}{ Health promotion behavior category } & \multirow[t]{2}{*}{$\chi^{2}$} & \multirow[t]{2}{*}{$\mathrm{df}$} & \multirow[t]{2}{*}{$\mathrm{p}$ value } \\
\hline & Inadequate & Minimal & Adequate & & & \\
\hline \multicolumn{7}{|l|}{ Age in years } \\
\hline Below 44 years & 2 & 1 & 1 & & & 0.50 \\
\hline $45-50$ years & 2 & 9 & 3 & & & \\
\hline $51-55$ years & 3 & 11 & 3 & & & \\
\hline $56-60$ years & 4 & 19 & 2 & 5.33 & 6 & \\
\hline \multicolumn{7}{|l|}{ Gender } \\
\hline Male & 7 & 21 & 6 & & & 0.65 \\
\hline Female & 4 & 19 & 3 & 0.87 & 1 & \\
\hline \multicolumn{7}{|l|}{ Marital status } \\
\hline Single & 1 & 2 & 1 & & & 0.77 \\
\hline Married & 8 & 35 & 7 & & & \\
\hline Widow/widower & 2 & 3 & 1 & 1.79 & 4 & \\
\hline \multicolumn{7}{|l|}{ Education } \\
\hline Primary education & 4 & 20 & 2 & & & 0.29 \\
\hline High school education & 4 & 14 & 2 & & & \\
\hline Higher secondary education & 1 & 3 & 2 & & & \\
\hline Graduation and above & 2 & 3 & 3 & 7.37 & 6 & \\
\hline \multicolumn{7}{|l|}{ Occupation } \\
\hline Employed & 7 & 9 & 6 & & & $0.01^{*}$ \\
\hline Unemployed & 2 & 28 & 2 & & & \\
\hline Retirement & 2 & 3 & 1 & 13.84 & 4 & \\
\hline \multicolumn{7}{|l|}{ BMI } \\
\hline $18.5-24.9$ & 7 & 19 & 5 & & & 0.18 \\
\hline $25.0-29.9$ & 2 & 20 & 3 & & & \\
\hline $30.0-34.9$ & 2 & 1 & 1 & 6.23 & 4 & \\
\hline \multicolumn{7}{|l|}{ Co morbidity status } \\
\hline Cardio vascular disease & 3 & 7 & 2 & & & 0.54 \\
\hline Hypertension & 4 & 19 & 3 & & & \\
\hline Chronic kidney diseases & 2 & 1 & 1 & & & \\
\hline None & 2 & 13 & 3 & 5.05 & 6 & \\
\hline \multicolumn{7}{|l|}{ Duration of diabetes } \\
\hline$<5 y r s$ & 7 & 5 & 6 & & & $0.01^{*}$ \\
\hline$>5 \mathrm{yrs}$ & 4 & 35 & 3 & 17.52 & 1 & \\
\hline \multicolumn{7}{|l|}{ Family history of DM } \\
\hline Yes & 4 & 12 & 7 & & & $0.03^{*}$ \\
\hline No & 7 & 28 & 2 & 7.12 & 1 & \\
\hline
\end{tabular}

$\mathrm{n}=60$.

$* \mathrm{p}<0.05$ level of significance.

\subsection{Strength and limitations}

The current study was conducted in a hospital setting and the recruitment of samples was successful with $100 \%$ response rate. There was no missing data in the data collection. The questionnaires used for the present study were developed by the researchers and validated by experts from nursing field. Some of the imitations existed in our study were noteworthy especially the study was done in a single setting with only a small sample of 60 participants. Absence of a random sampling technique was anotherissue. So the generalisation of findings should be done with caution. Also the study has not included current medication regime and adherence to it and most of the questions included in HPB questionnaire were self reported.

\subsection{Implications of the study}

More intensive training and education in health promotion behaviour can be planned in diabetic clinics. A diabetic nurse educator can identify the needs and provide individual based education and awareness among patients. Development of a health promotion behaviour programme and further monitoring of its effects can be planned. Monthly or once in three months compliance report can be initiated in hospital to evaluate patients adherence to healthy behaviours. Non compliance to the programme can be tackled with motivation and counselling sessions.

\subsection{Recommendations for future studies}

Further studies can be planned with newer interventions to improve health promotion behaviours. Well designed randomised controlled trials can be conducted. A future study can be planned in community setting by comparing difference between urban and rural people. Since diabetes and coronary artery disease are closely related, a future study can be done to assess the knowledge and risk of CAD in diabetes patients.

\section{Conclusion}

Toc conclude Health promoting behaviour was practiced by a low proportion of diabetes patients in the current study. Being relatively low obtained scores for HPB, it seems to need specific attention to promote strategies for improving health promotional behaviours. Individually tailored interventions and public health interventions can be beneficial by focussing on diet, exercise, risk reduction and stress management.

\section{Funding}

The authors have not received any kind of funding from any of the sources for this research project. 


\section{Declaration of competing interest}

None declared by the authors with respect to research, authorship and/or publication of this article.

\section{References}

1. World Health Organization. Diabetes key facts. Retrieved from https://www.who. int/en/news-room/fact-sheets/detail/diabetes; 2018

2. Pandey SK, Sharma V. World diabetes day 2018: battling the emerging epidemic of diabetic retinopathy. Indian J Ophthalmol. 2018 Nov;66(11):1652.

3. Baghbanian A, Tol A. The introduction of self-management in type 2 diabetes care: a narrative review. J Educ Health Promot. 2012;1. https://doi.org/10.4103/2277-9531. 102048.

4. Bains SS, Egede LE. Associations between health literacy, diabetes knowledge, selfcare behaviors, and glycemic control in a low income population with type 2 diabetes. Diabetes Technol Therapeut. 2011 Mar 1;13(3):335-341.

5. Kim S, Love F, Quistberg DA, Shea JA. Association of health literacy with self-management behavior in patients with diabetes. Diabetes Care. 2004 Dec 1;27(12):2980-2982.

6. McCleary-Jones V. Health literacy and its association with diabetes knowledge, selfefficacy and disease self-management among African Americans with diabetes mellitus. ABNF J. 2011 Apr 1;22(2).

7. Al Sayah F, Majumdar SR, Egede LE, Johnson JA. Associations between health literacy and health outcomes in a predominantly low-income African American population with type 2 diabetes. J Health Commun. 2015;20(5):581-588.

8. Eyüboğlu E, Schulz PJ. Do health literacy and patient empowerment affect self-care behaviour? A survey study among Turkish patients with diabetes. BMJ open. 2016 Mar 1;6(3):e010186.

9. Wysham CH, Kirkman MS. American diabetes association. Standards of medical care in diabetes-2011. Diabetes Care. 2011;34(Suppl. 1):S11-S61 Diabetes care. 2011 May 1;34(5):e54.

10. Knowler WC, Barrett-Connor E, Fowler SE, et al. Reduction in the incidence of type 2 diabetes with lifestyle intervention or metformin. N Engl J Med. 2002 Feb;346(6):393-403.

11. Hamman RF, Wing RR, Edelstein SL, et al. Effect of weight loss with lifestyle intervention on risk of diabetes. Diabetes Care. 2006 Sep 1;29(9):2102-2107.
12. Laaksonen DE, Lindström J, Lakka TA, et al. Physical activity in the prevention of type 2 diabetes: the Finnish diabetes prevention study. Diabetes. 2005 Jan 1;54(1):158-165.

13. Tuomilehto J, Lindström J, Eriksson JG, et al. Prevention of type 2 diabetes mellitus by changes in lifestyle among subjects with impaired glucose tolerance. $N$ Engl J Med. 2001 May 3;344(18):1343-1350.

14. Chen MY, Huang WC, Peng YS, et al. Effectiveness of a health promotion programme for farmers and fishermen with type-2 diabetes in Taiwan. J Adv Nurs. 2011 Sep;67(9):2060-2067.

15. Chen CP, Peng YS, Weng HH, Yen HY, Chen MY. Health-promoting behavior is positively associated with diabetic control among type 2 diabetes patients. Open J Nurs. 2013 May 31;3(2):274.

16. Jones H, Edwards L, Vallis TM, et al. Changes in diabetes self-care behaviors make a difference in glycemic control: the Diabetes Stages of Change (DiSC) study. Diabetes Care. 2003 Mar 1;26(3):732-737.

17. Rosiek A, Kornatowski T, Frackowiak-Maciejewska N, Rosiek-Kryszewska A, Wyżgowski P, Leksowski K. Health behaviors of patients diagnosed with type 2 diabetes mellitus and their influence on the patients' satisfaction with life. Therapeut Clin Risk Manag. 2016;12:1783.

18. Sampaio FA, Melo RP, Rolim IL, Siqueira RC, Ximenes LB, Lopes MV. Evaluation of the health promotion behavior in patients with diabetes mellitus. Acta Paul Enferm. 2008 Mar;21(1):84-88.

19. Tol A, Mohebbi B, Sadeghi R, Maheri AB, Eshraghian MR. Determinants of healthpromoting behaviors among type 2 diabetic patients: voice of Iran. Open J Endocr Metab Dis. 2014;4(9):219.

20. Abd-Allah ES, Metwally AS, Abd El Mohsen AS, Shafik SA. Assessment of health promoting behaviors AmongElderly diabeticsatoutpatient diabetic clinic helwan general hospital. IOSR J Nurs Health Sci. 2017;6(6):57-66.

21. Friis K, Vind BD, Simmons RK, Maindal HT. The relationship between health literacy and health behaviour in people with diabetes: a Danish population-based study. $J$ Diabetes Res. 2016.

22. Chen CP, Peng YS, Weng HH, Yen HY, Chen MY. Health-promoting behavior is positively associated with diabetic control among type 2 diabetes patients. Open J Nurs. 2013 May 31;3(2):274.

23. Al-Rubeaan K, Al-Manaa HA, Khoja TA, et al. Epidemiology of abnormal glucose metabolism in a country facing its epidemic: SAUDI-DM study. J Diabetes. 2015 Sep;7(5):622-632.

24. El-Khawaga G, Abdel-Wahab F. Knowledge, attitudes, practice and compliance of diabetic patients in Dakahlia, Egypt. Euro J Res Med Sci. 2015;3(1). 